\title{
Ischemic Stroke in COVID-19 Patients May Be Incidentally but Not Causally Related to the Infection
}

\author{
Josef Finsterer ${ }^{a}$ Fulvio A. Scorza ${ }^{b}$ \\ ${ }^{a}$ Klinikum Landstrasse, Messerli Institute, Vienna, Austria; ${ }^{b}$ Disciplina de Neurociência, Escola Paulista de \\ Medicine/Universidade Federal de São Paulo/(EPM/UNIFESP), São Paulo, Brazil
}

Dear Editor,

With interest we read the article by Saggese et al. [1] about a 62-year-old man with an acute ischemic stroke in the context of a SARS-CoV-2 infection with minimal manifestations. Consecutively, the patient experienced further thromboembolic events. It was concluded that infections with SARS-CoV-2 favor the development of ischemic stroke [1]. We have the following comments and concerns.

SARS-CoV-2 infections may cause complications as any other infection. One of these complications is ischemic stroke. Ischemic stroke in SARS-CoV-2-infected patients may be explained by exsiccosis, hypercoagulability, immobility, heart failure, chronic obstructive lung disease, obesity, or arrhythmias triggered by the infection. Ischemic stroke in SARS-CoV-2-infected patients may also result from intraventricular thrombus formation due to a Takotsubo syndrome, increasingly reported in COVID-19 patients [2].

As millions of patients got infected since the onset of the pandemic but only very few experienced an ischemic stroke [3], an increased prevalence of ischemic stroke in SARS-CoV-2-infected patients is questionable. Anyhow, we agree that this point requires further investigations.
However, the risk of experiencing an ischemic stroke during an infection with SARS-CoV-2 may be increased among those with a high cardiovascular risk profile. The best example is the index case. The patient had a high-risk profile (arterial hypertension, diabetes, history of smoking, and previous myocardial infarction requiring placement of a stent) and was generally at an increased risk of experiencing a cerebrovascular event. In patients with a high-risk profile, a minor trigger may be enough to reduce cerebral perfusion below a critical cut-off. Such discrete triggers can be easily forwarded, for example, by any viral infection.

Whether the infection with SARS-CoV-2 promotes hypercoagulability or not is under debate but conceivable. Assuming that the infection generally leads to a hypercoagulable state, it is warranted that all patients with a symptomatic SARS-CoV-2 infection are anticoagulated. However, the relatively low number of patients with thrombotic or embolic events $(0.7 \%$ of those hospitalized for COVID-19) [3] argues against a generally increased hypercoagulable state.

Missing in this report is a carotid ultrasound. Missing is also the multimodal MRI to assess the acuity and dynamics of the ischemic lesion. Additionally, missing is the karger@karger.com www.karger.com/ced

(C) 2021 S. Karger AG, Base

Karger!
Josef Finsterer

Klinikum Landstrasse, Messerli Institute Postfach 20

AT -1180 Vienna (Austria)

fipaps@yahoo.de 
classification of the stroke as embolic or atherosclerotic, and the exclusion of a neoplasm.

We do not agree that dysgeusia is due to affection of the central nervous system (CNS) by the infection [4]. In the vast majority of the cases with CNS involvement in the infection, the cerebrospinal fluid is negative for the virus [Finsterer, submitted], suggesting that rather the cytokine storm is responsible for CNS impairment and that CNS complications are rather immune-mediated than directly attributable to the virus.

Overall, it is quite likely that patients with known micro- or macroangiopathy are at an increased risk of experiencing a cardio-embolic event during an infection with SARS-CoV-2. Whether the infection is generally associated with an increased cerebrovascular risk or leads to a hypercoagulable state remains questionable, but in case there is hypercoagulability, SARS-CoV-2-infected patients need to undergo anticoagulation if there is no con- traindication. Whether symptomatic patients with a SARS-CoV-2 infection profit from steroids for immunemediated adverse reactions needs to be investigated.

\section{Conflict of Interest Statement}

There are no conflicts of interest.

\section{Funding Sources}

No funding was received.

\section{Author Contributions}

J.F.: design, literature search, discussion, first draft, and critical comments.

\section{References}

1 Saggese CE, Del Bianco C, Di Ruzza MR, Magarelli M, Gandini R, Plocco M. COVID-19 and stroke: casual or causal role? Cerebrovasc Dis. 2020;49(3):341-4.

2 Kariyanna PT, Chandrakumar HP, Jayarangaiah A, Khan A, Vulkanov V, Ashamalla M, et al. Apical takotsubo cardiomyopathy in a COVID-19 patient presenting with stroke: a case report and pathophysiologic insights. Am J Med Case Rep. 2020;8(10):350-7.
3 Annie F, Bates MC, Nanjundappa A, Bhat DL, Alkhouli M. Prevalence and outcomes of acute ischemic stroke among patients $\leq 50$ years of age with laboratory confirmed COVID-19 infection. Am J Cardiol. 2020 Sep 1; 130:169-70.

4 Finsterer J, Stollberger C. Causes of hypogeusia/hyposmia in SARS-CoV2 infected patients. J Med Virol. 2020 Oct;92(10):1793-4. 